\title{
HACIA UNA DIÓCESIS NUEVA CON EL PAPA FRANCISCO
}

\section{TOWARDS A NEW DIOCESE WITH POPE FRANCIS}

Juan Alberto Osorio Torres*

\begin{abstract}
RESUMEN
Se destaca la importancia que tiene la diócesis como unidad social, para el proyecto de reforma estructural de la Iglesia, a la que el Papa Francisco ha emplazado en su primera carta La alegría del Evangelio. Este proyecto significa una verdadera refundación de la diócesis, porque le demanda a la Iglesia su retorno al Evangelio, y le recuerda su condición de sujeto primario de esta reforma estructural. Desde la antropología de la diócesis, se muestra la temprana contribución a este proceso de parte de la Arquidiócesis de Lima, de 1954 a 1996. A causa de esta experiencia, la diócesis dejó de funcionar como una estructura simbólica de poder de arriba hacia abajo, debido a que las oleadas migratorias y sus protagonistas provincianos, consiguieron transformar desde abajo y desde dentro el ejercicio de ese poder, volteando e invirtiendo su convencional orientación.
\end{abstract}

PALABRAS CLAVE: Evangelio, conversión pastoral, clericalismo, diócesis, reforma, poder, antropología de la diócesis.

\begin{abstract}
The importance of the diocese as a social unit for the project about structural reform of the Church is highlighted; which the Pope Francis has set in his first letter, "The joy of the Gospel". This project means a real foundation of the diocese, because it demands the return of the Church to the Gospel, and reminds it its condition as primary subject of this structural reform. From an anthropological approach of the diocese, the early contribution to this process of the Archdiocese of Lima from 1954 to 1996 is spelled out. Due to this experience, the diocese ceased to function as a symbolic powerstructure from top to bottom, because the migratory waves and provincial protagonists succeeded in transforming from below and from within the exercise of that power, turning and reversing its conventional orientation.
\end{abstract}

\section{KEYWORDS:}

Gospel, pastoral conversion, clericalism, diocese, reform, power, anthropology of the diocese.

Sacerdote y Docente de la Universidad Femenina del Sagrado Corazón: josoriot@unife.edu.pe 
"Quiero lío en las diócesis, quiero que se salga afuera, quiero que la Iglesia salga a la calle..."

\section{INTRODUCCIÓN}

En su primera carta apostólica, La alegría del Evangelio (2013), el papa Francisco ha plasmado su pensamiento y su programa pontificio para las siguientes décadas de la obra evangelizadora de la Iglesia universal. "En esta Exhortación quiero dirigirme a los fieles cristianos para invitarlos a una nueva etapa evangelizadora marcada por esa alegría, e indicar caminos para la marcha de la Iglesia en los próximos años." (n. 1).

Aunque el Papa no lo dice explícitamente ni lo ha formulado con idénticos términos, el diagnóstico de la realidad eclesial que nos ofrece en su exhortación, mueve a suponer que su convocatoria a "ser audaces y creativos" tiene el propósito de "repensar los objetivos, las estructuras, el estilo y los métodos evangelizadores de las propias comunidades" (n. 33), para llevar a cabo con él una verdadera refundación de la diócesis.

Presento a continuación, una reflexión teológico pastoral que, inspirada en la lectura de la primera carta del primer papa latinoamericano, intenta acceder a una comprensión mayor de la naturaleza social y del funcionamiento pastoral de la Iglesia particular o diócesis, desde una perspectiva antropológica. Con tal propósito, primero desprendo de su exhortación, algunas importantes características de la diócesis nueva que, por negación, el Papa echa de menos en el actual panorama eclesial.

En segundo lugar, a partir de la consideración de tales características desde la perspectiva de la llamada antropología de la diócesis, formulo un concepto de Iglesia particular acorde y capaz de responder al diagnóstico y el propósito misionero que el nuevo Papa viene aplicándole a la reforma estructural de la Iglesia. Aplico, en tercer lugar, esta definición y este enfoque antropológico para analizar e interpretar la experiencia eclesial pastoral con que la Arquidiócesis de Lima resultó concibiendo, gestando y alumbrando al fin del pasado milenio las trillizas diócesis nuevas de Carabayllo, Chosica y Lurín, que hoy transitan recién los tres lustros de fundación. Y, concluyo, llamando a adherirnos al proyecto del Papa Francisco, reanudando y actualizando los cambios eclesiales conquistados y a cultivar y hacer florecer los logros pastorales obtenidos en el Perú a lo largo de la segunda mitad del siglo XX.

\section{RASGOS DE LA DIÓCESIS NUEVA QUE SE DESPRENDEN DE LA ALEGRÍA DEL EVANGELIO}

Como se desprende de su primera carta "La alegría del Evangelio", lo que el Papa Francisco persigue es, comunicar

1 Papa Francisco, Jornada Mundial de la Juventud, Río 25 de Julio 2013

Dedico el presente artículo a Jaime Madden, sacerdote misionero Maryknoll, recientemente fallecido entre los suyos el 09-01-14. Porque su doloroso testimonio de rechazo y de inexplicable expulsión, es una prueba más de la clamorosa necesidad de reforma estructural de la Iglesia, a partir de una administración verdaderamente evangélica de la diócesis, a la que el Papa Francisco viene instando desde el primer día de su elección. Porque, al año de celebrada la V Conferencia del CELAM Aparecida, en la que se nos pidió una Iglesia de discípulos misioneros, el 2008 el nuevo obispo de Juli sin mediar explicación "invitó" a Jaime y sus hermanos misioneros a interrumpir su tenaz presencia de 50 años de labor reconocida por la Iglesia, el país y la sociedad local de la Prelatura de Juli, a la que sirvieron desde 1957. Junto con los otros sacerdotes de la congregación Roberto Hoffman, Edmundo Cookson y Miguel Briggs, Jaime Madden fue uno de los expulsados, que debió pasar entonces a servir a la diócesis de Puno. 
a obispos, sacerdotes y laicos de todo el mundo, su apuesta por la formación de una diócesis 'nueva'. Y para que sea posible este "volver a la fuente y -poderrecuperar la frescura del Evangelio" (n. 11), lo que básicamente espera de la Iglesia es, verla comprometida a fondo asumiendo una doble exigencia: la de la conversión pastoral y, como consecuencia de ella, la inclusión social de los pobres como su opción preferencial ${ }^{2}$. Porque, como él lo advierte, es del retorno a 'la fuente' que brotan otras formas de expresión cargadas de renovado significado para el mundo actual" (n. 11).

\subsection{Conversión pastoral}

Desde el primero de los cinco capítulos de La Alegría del Evangelio, Papa Francisco abre el primer tema -Iglesia en salida- a partir de la conversión pastoral, tras señalar que lo que se propone es expresar algo que "tiene un sentido programático y consecuencias importantes..." (n. 25). Y no lo cierra, sin antes preguntar por el perfil de la parroquia y después de espolear el funcionamiento de la diócesis, al punto de alertar de manera explícita y rotunda sobre los graves peligros que se ciernen sobre las estructuras eclesiales: es decir, que "ya no nos sirve una simple administración" (n.
25). Y que, "cualquier estructura nueva se corrompe" (n. 26).

Efectivamente, en el pasado colonial del siglo XVI, las diócesis se erigieron con éxito, aunque a base de profanación y saqueo, extirpación de idolatrías y masacre. Basta revisar la situación a la que fue reducido el sistema religioso prehispánico a partir de la suerte que corrió en nuestro caso andino y limeño, el santuario de Pachacamac, en su sacralidad y sus fortunas, a las pocas semanas de la captura de Atahualpa en Cajamarca (Curátola 2013, p. 737741). O, basta explorar las intenciones de extirpadores como el cura Francisco de Ávila, quien aunque hurgando en 1608 en el sistema de creencias y ritos de los antiguos peruanos de Huarochirí, resultó legando la visión indígena de la conquista en un manuscrito traducido siglos después en el Perú por José María Arguedas (González 2013, p. 526) y Gerald Taylor (1987), entre otros. En el siglo XX, y en relación con la pederastia clerical, no pocas de las diócesis en el mundo involucradas en este atentado, dieron la espalda a las víctimas para proteger al victimario menoscabando la credibilidad y la institucionalidad eclesial, mientras respecto a este abuso, tales diócesis fueron administradas a base de trampas, ocultamientos y complicidad,

2 El Documento de Aparecida inspiró a los miembros de la Diócesis de Lurín, reunidos en su V Asamblea 2008, a fundamentar la redacción de su Plan Pastoral, sobre la base de siete ejes pastorales, entre los cuales, figura el de conversión pastoral y el de la opción preferencial por los pobres.

3 En estas semanas de Julio 2014, el Papa Francisco está pidiendo "perdón por la "omisión" de la Iglesia frente a los abusos sexuales". "Algunas víctimas optaron por el suicidio. Las muertes de estos hijos amados de Dios pesan en la conciencia mía y de toda la Iglesia". "Humildemente pido perdón", dijo el papa argentino, quien reconoció que los líderes de la Iglesia "no han respondido adecuadamente a las denuncias de abuso presentadas por familiares y por aquellos que fueron víctimas del abuso". (...) En otro momento de su intervención, el papa expresó su "angustia y dolor por el hecho de que algunos sacerdotes y obispos hayan violado la inocencia de menores y su propia vocación sacerdotal al abusar sexualmente de ellos. Es algo más que actos reprobables". (...) Bergoglio, finalmente, condenó estos actos que, sostuvo, "han dejado cicatrices para toda la vida". (Diario La República, martes 8 de julio 2014, Lima-Perú). Días después, agregó enérgico e indignado "su preocupación por las estadísticas que le ofrecen algunos de sus colaboradores, que apuntan a que la pederastia podría afectar al $2 \%$ de la Iglesia. "Lo considero gravísimo. Este $2 \%$ de pederastas son incluso obispos y cardenales. Además, otros conocen estos casos y callan. Encuentro esta situación insostenible y mi intención es afrontarla con la severidad que requiere", subrayó el Papa Francisco." (13 julio 2014) 
de los que antes que las propias diócesis, fue la prensa la que se encargó de dar a conocer el delito ${ }^{3}$. Aunque ciertamente, solo refiriéndose de manera implícita a este grave crimen, parafraseando a Pablo VI, Francisco observa que "brota, por lo tanto, un anhelo generoso y casi impaciente de renovación, es decir, de enmienda de los defectos que denuncia y refleja la conciencia, a modo de examen interior, frente al espejo del modelo que Cristo nos dejó de sí" (n. 26).

Si bien Francisco, para referirse a esta unidad eclesial, menciona en toda su carta solo cuatro veces a la iglesia particular y apenas dos a la diócesis, sin embargo, en un tono nuevamente interpelante, once veces hace referencia explícita a las estructuras eclesiales, para señalar sin rodeos: "Hay estructuras eclesiales que pueden llegar a condicionar un dinamismo evangelizador; igualmente las buenas estructuras sirven cuando hay una vida que las anima, las sostiene y las juzga. Sin vida nueva y auténtico espíritu evangélico, sin «fidelidad de la Iglesia a la propia vocación», cualquier estructura nueva se corrompe en poco tiempo."(n. 26) Es decir, una estructura nueva, por más eclesial que sea y por más alta estructura jerárquica formal y oficial que ostente, es una estructura de poder tan capaz de todo, que puede corromperse en corto tiempo.

Dicho esto, enseguida, el Papa latinoamericano confiesa con el corazón en la mano: "Sueño con una opción misionera capaz de transformarlo todo, para que las costumbres, los estilos, los horarios, el lenguaje y toda estructura eclesial se convierta en un cauce adecuado para la evangelización del mundo actual más que para la autopreservación." (n. 27) De esta manera, cuando el Papa examine primero, el trabajo pastoral de las parroquias y recuerde que ella "no es una estructura caduca", de plano pedirá revisar y renovar su funcionamiento porque sus frutos han resultado insuficientes. Para Francisco, las parroquias no son solidarias: porque "no están más cerca de la gente"; no son críticas: porque "no son ámbitos de viva comunión y participación"; ni son públicas: porque "no se orientan completamente a la misión". (n. 28) Y cuando se refiere a las diócesis, declarará su incapacidad para lograr el sueño misionero de llegar a todos (n. 31). Al evaluar, incluso, el ejercicio del papado, y citando a Juan Pablo II califica de escaso el avance a una situación nueva a causa de "una excesiva centralización" (n. 32), lo cual sigue demorando la anhelada colegialidad y la justa autonomía de las Conferencias Episcopales que las constituya en sujetos de atribuciones concretas, incluyendo alguna auténtica autoridad doctrinal (n. 32).

Defendiendo el lugar y papel del laico, tras demandar que el cura se esfuerce por ser pastor con olor a oveja, el Pontífice entabla lío por un doble y considerable motivo. En primer lugar, porque en su larga experiencia pastoral le consta que "los laicos no encuentran espacio en sus Iglesias particulares para poder expresarse y poder actuar...". Y en segundo lugar, porque como es de conocimiento público y de larga data, la causa fundamental de este endémico problema tiene su raíz en "un excesivo clericalismo que los mantiene - a los laicos- al margen de las decisiones" (n. 102)4.

http://www.periodistadigital.com/religion/vaticano/2014/07/13/es-gravisimo-un-dos-por-ciento-depederastas-son-incluso-obispos-y-cardenales-otros-conocen-estos-casos-y-callan-religion-iglesiafrancisco-vaticano-scalfari-celibato-mafia.shtml)

4 Desde la publicación de la Christifideles laici, la considerada "carta de ciudadanía del laico", que critica la tendencia a la clericalización (23f), ningún papa como Francisco había sido tan explícito en considerar la gravedad del clericalismo. A menos de un mes de publicada su Alegría del Evangelio, Francisco señalaba 
Deseando aclarar que en la Iglesia no hay superiores ni inferiores, puesto que las funciones "no dan lugar a la superioridad de los unos sobre los otros", Francisco hace tres precisiones fundamentales. Da por suprimida la supuesta verticalidad y asimetría simbólica dominante, masculina y clerical del arriba-abajo, recordando a la vez, que hay que evitar confundir la potestad sacramental del sacerdote y su función con la dignidad y con la santidad; que "la gran dignidad viene del Bautismo, que es accesible a todos"; y sobre todo que, María de Nazareth, "es más importante que los obispos, por ser mujer, antes que por ser la madre de Dios" (n. 104).Y como claramente señaló en tono indignado en la JMJ de Río 2013, después de pedirles que "hagan lío en las diócesis...", los jóvenes son en la Iglesia, fuente de esperanza y los ancianos, fuente de memoria y sabiduría, ambos, los grandes protagonistas de la Iglesia y la sociedad (n. 106).

En ese marco, hay que tener presente lo que dijo en Brasil, hallándose en medio de los jóvenes del continente. Que para corregir y mejorar lo que la Iglesia tiene el deber de hacer en el mundo "hacen falta obispos que amen la pobreza y que no tengan psicología de príncipes, que no sean ambiciosos, que sean esposos de una Iglesia, sin estar a la expectativa de otra, esperando la promoción. Deben velar por la esperanza de su pueblo" 5 .
Al obispo le recuerda que su deber es poner en marcha los mecanismos de participación que le permita llegar "no sólo a algunos que le acaricien los oídos", sino a todos y todos a él". (n. 31) En ese tono de reproche paternal, que indica por una parte su rechazo de cualquier complicidad y encubrimiento, señalando por otra, que no todo se ha echado a perder, Francisco advierte a los obispos que se trata de huir de la corrupción o de deslindar con el crimen, pero no solo por quedar bien, ni por pura autopreservación (n. 27).

\subsection{Inclusión social de los pobres}

Para el Papa Francisco, hablar de la opción preferencial por los pobres, es coronar y poner en evidencia lo que implica y exige una auténtica conversión pastoral y social, y responder, real y efectivamente a la necesidad de ser audaces y creativos para "repensar las estructuras" comprometiendo "la guía de los obispos" (n. 33).

Por un lado, Francisco recuerda y recomienda que "hoy y siempre, «los pobres son los destinatarios privilegiados del Evangelio», y que la evangelización dirigida gratuitamente a ellos es signo del Reino que Jesús vino a traer. Hay que decir sin rodeos que existe un vínculo inseparable entre nuestra fe y los pobres. Nunca los dejemos solos." (n. 48). En el contexto de esta frase es que agrega otra

que "cuando falta profecía el clericalismo ocupa su sitio ««Cuando falta la profecía, el clericalismo ocupa su sitio, el rígido esquema de la legalidad que cierra la puerta en la cara al hombre. Por ello la oración para que, en la perspectiva de la Navidad, el espíritu de la profecía se haga sentir en el pueblo». (...) El Papa Francisco concluyó su homilía proponiendo «una oración en estos días que nos preparamos para el Nacimiento del Señon. Una oración al Señor para que —invocó- «no falten profetas en tu pueblo. Todos nosotros, bautizados, somos profetas. Señor, que no olvidemos tu promesa; que no nos cansemos de seguir adelante; que no nos cerremos en las legalidades que cierran las puertas. Señor, libera a tu pueblo del espíritu del clericalismo y ayúdale con el espíritu de profecía» (Papa Francisco, 1612-2013).

5 Discurso del papa Francisco en el encuentro con el Comité de coordinación del CELAM en el Centro de Estudios de Sumaré (Río de Janeiro, 28 julio 2013). 
que se ha hecho ya clásica para acicatear la conversión pastoral de la estructura: "...prefiero una Iglesia accidentada, herida y manchada por salir a la calle, antes que una Iglesia enferma por el encierro y la comodidad de aferrarse a las propias seguridades. No quiero una Iglesia preocupada por ser el centro y que termine clausurada en una maraña de obsesiones y procedimientos." (n. 49). La Iglesia, opta por los pobres por motivos teológicos, antes que por simple lástima, paternalismo o tutelaje, y no solo por razones culturales, sociológicas, políticas o filosóficas (n. 198).

Por eso, Francisco defiende el potencial crítico de los pobres, y su puesta en evidencia del fracaso de los poderosos, su capacidad de iniciativa, de autodeterminación y de organización: "Algunos simplemente se regodean culpando a los pobres y a los países pobres de sus propios males, con indebidas generalizaciones, y pretenden encontrar la solución en una «educación» que los tranquilice y los convierta en seres domesticados e inofensivos. Esto se vuelve todavía más irritante si los excluidos ven crecer ese cáncer social que es la corrupción profundamente arraigada en muchos países —en sus gobiernos, empresarios e institucionescualquiera que sea la ideología política de los gobernantes." (n. 60)

Por otro lado, como jamás había sido explicitada antes, -salvo por Juan XXIII-, para Francisco esta predilección por el pobre, está motivada por su propósito de "hacer una iglesia pobre para los pobres" (n. 198). Porque para la Iglesia, solo ellos, los pobres y sencillos pueden conocer lo que es tener sed de Dios (n. 123). Porque su piedad popular, que a partir de Aparecida posee rango de espiritualidad o mística popular, "es una manera legítima de vivir la fe, un modo de sentirse parte de la Iglesia y una forma de ser misioneros (n. 124). Además, porque, para Dios y para esta opción, el pobre no tiene precio, no se negocia, vale demasiado. Ya que "el pobre, cuando es amado, «es estimado como de alto valor», y esto diferencia la auténtica opción por los pobres de cualquier ideología, de cualquier intento de utilizar a los pobres al servicio de intereses personales o políticos." (n. 200). Porque, si algún denso y extenso sector social es movido aún por la esperanza en un cambio, no es otro que particularmente el conformado por los pobres, para quienes "en medio de la oscuridad siempre comienza a brotar algo nuevo, que tarde o temprano produce un fruto" (n. 276).

\section{NUEVO CONCEPTO DE DIÓCESIS PARA EL SIGLO XXI}

Sin desmerecer el lugar que le corresponde al derecho canónico y a los documentos pontificios dedicados por los últimos papas a la misión, identidad y funciones del obispo en la marcha de la diócesis ${ }^{6}$, lo que el Papa latinoamericano está haciendo, con la publicación de La alegría del Evangelio, es corregir y enriquecer la comprensión de la naturaleza y del funcionamiento de la Iglesia particular. La diócesis es, para Francisco, una unidad eclesiástica, y por eso mismo, una unidad de carácter particularmente social. Es lo que viene mostrando desde el primer día de su elección, amalgamando la fuerza simbólica de sus gestos de Papa

6 Directorio para el ministerio de pastoral de los obispos a la luz del Sínodo de los obispos, 2001; Pastores gregis, 2003; Apostolorum Successores, 2004. 
latinoamericano con la urgencia y la audacia de sus mensajes ${ }^{7}$.

Tomando distancia tanto de optimismos ingenuos como de fatalismos irreversibles (nn. 84 y 96) antes de definir conceptualmente la diócesis, Francisco evalúa su comportamiento institucional considerando que en definitiva, ella, como "porción de la Iglesia católica bajo la guía de su obispo, también está llamada a la conversión misionera" (n. 30). Porque su identidad y naturaleza, inclusive su porvenir, lo ameritan sobremanera -sin ocultar ni justificar errores y pecados propios- a causa de "la rica tradición bimilenaria de la Iglesia" (n. 233), y de su trayectoria histórica de luces y no menos de sombras arriba aludidas, de alguna manera incluidas reiteradamente por el Papa (nn. 26, 27,7 6, 83, 84, 93, $95,129,131)$. Llama la atención que, al tratar de definir en su carta el concepto de iglesia particular o diócesis, aunque retomando términos jurídicos, el Papa no cita explícitamente el derecho canónico de 1983, canon 369, pero sí, deplora y rechaza explícitamente el clericalismo (n. 102).

Recordando que, antes que "una institución orgánica y jerárquica", el sujeto de la evangelización es "ante todo un pueblo que peregrina hacia Dios" (n. 111); el Papa explica que, "parte de nuestro pueblo bautizado no experimenta su pertenencia a la Iglesia", tanto por "unas estructuras y un clima poco acogedores en algunas de nuestras parroquias y comunidades...", como por la preeminencia de una "actitud burocrática para dar respuesta a los problemas, simples o complejos, de la vida de nuestros pueblos" (n. 63). Para cualquier imagen autocomplaciente de la Iglesia muy satisfecha de sí misma, que piensa que es el mundo y que son los demás los que necesitan convertirse, el Papa pide tener muy en cuenta que "en muchas partes hay un predominio de lo administrativo sobre lo pastoral, así como una sacramentalización sin otras formas de evangelización" (n. 63).

Por todo esto, una vez hecha 'partícipe' del proceso de conversión pastoral, le recuerda a la diócesis su identidad de 'sujeto' y tras haberla involucrado en sus implicancias evangélicas más profundas, le reanuda y reintegra su misión de 'artífice' y de verdadero protagonista en el proceso de renovación de las estructuras eclesiales, al caracterizarla de una triple forma. En primer lugar, al signarla como "sujeto primario de la evangelización". En segundo lugar, al identificarla como "manifestación concreta de la única Iglesia en un lugar del mundo". Y en tercer lugar, al reconocerla como "la Iglesia de Cristo, Santa, Católica y Apostólica que está en ella" (n. 30).

Tal conjunto de datos arriba señalados, acerca del perfil de pastores con "olor a oveja", como del "santo pueblo fiel de Dios", subordinados a la conversión pastoral y a la inclusión social de los pobres, conforman la unidad de criterios a partir de la que el Papa está implícitamente demandando y

7 Es muy pertinente y significativa fuente de gozo esta conquista y verdadera reivindicación de la dimensión social de la fe, por parte del Papa argentino. Porque, para el enfoque del quehacer pastoral de la Iglesia de hoy y de siempre, la dimensión social, es el componente ineludible del Evangelio, aunque a veces brille por su ausencia, en nombre de cierto espiritualismo desencarnado, al que, desde Medellín a Aparecida, se nos tiene siempre alertas. De las 74 veces que es citada la palabra social en la carta del Papa, tres son dedicadas a la dimensión social del Evangelio (88-177-258) y todo el capítulo IV a la dimensión social de la evangelización.

8 Homilía del Jueves Sacerdotal de Semana Santa 2014. 
elaborando una definición más pastoral y un tratamiento más antropológico de la diócesis, de lo que tal vez puede dar cuenta la llamada antropología de la diócesis9. A partir de la experiencia eclesial vivida en Lima 1954-1996, la antropología de la diócesis, da cuenta de la identidad colectiva de la Iglesia y de su carácter de unidad social. Esta perspectiva, procedente de las ciencias sociales, descubre en la iglesia particular, la estructura angular fundamental en cuyo evangélico funcionamiento pastoral y social está en juego la presencia, la pertenencia y sobre todo incidencia tanto interna, como sobre todo pública de la Iglesia católica en la actualidad ${ }^{10}$.

La antropología de la diócesis, intenta responder a la pregunta por la significación antropológica del nacimiento y funcionamiento de la diócesis como unidad social, que desde su origen pre cristiano y durante toda su trayectoria cristiana funcionó como estructura simbólica de poder asimétrico, vertical y piramidal. Ella, busca y elabora una definición, que ayude a comprender -e incluso intente transformar el presente estado de inercia diocesano, advertido por el Papa, y al que tras el 'aggiornamento' de los primeros años del postconcilio, el funcionamiento anterior de la iglesia particular, parece haber retornado en el mundo actual, y del que muchas diócesis, particularmente las de Lima y resto de Perú, empezaron a salir desde fines de los años sesenta, a partir de Medellín (Evangelización y crecimiento de la fe 6.1 $)^{11}$. La Arquidiócesis de Lima, tres meses después de realizada la Conferencia de Medellín, al concluir su XXXVI Asamblea Episcopal, cuyo objetivo fue aplicar las conclusiones de esta II Conferencia Latinoamericana a la marcha de la Iglesia en el Perú, concluyó, entre otros, con el siguiente sugerente acuerdo:

"En nuestras diócesis denunciaremos enérgicamente los abusos y las injustas consecuencias de las desigualdades excesivas entre ricos y pobres, entre poderosos y débiles, acompañando tales denuncias, si fuera necesario con gestos concretos de solidaridad para con los pobres y oprimidos. (2.4.6.) A los sacerdotes, religiosos y laicos comprometidos con los pobres en el proceso de liberación de nuestro país les expresamos nuestro deseo de estar siempre muy cerca de ellos (...) para que sientan nuestro aliento y sepan que

9 Es lo que el antropólogo jesuita, Manuel Marzal, de manera ambiciosa, se propuso y dejó muy encaminado antes de fallecer. Y, que como autor de este artículo, sustenté recientemente en la tesis de doctorado Tradición y utopía pastoral. Antropología de la diócesis desde el nacimiento de la Diócesis de Lurín 19541996, en la PUCP, el 11 de diciembre de 2013, que se encuentra disponible online en http://tesis.pucp. edu.pe/repositorio/handle/123456789/5205

10 El Papa Francisco alienta en carta a reflexionar teológicamente en diálogo con las ciencias sociales $(40,132,133,182,242,243)$.

11 En general, dentro y fuera de Lima, la pertenencia católica de los adolescentes y universitarios de hoy, cuenta con una abundante aunque dispersa información carente de balance alguno, serio y documentado, acerca del fecundo caminar de la Iglesia Católica, durante los años 70 a los 90, cuando los padres de estos jóvenes fueron adolescentes y jóvenes. Sin prescindir de los datos del centenar de páginas entregadas por el Informe Final de la Comisión de la Verdad y Reconciliación (Vol. III 385490), no obstante, debe tenerse en cuenta el trabajo de Fernando Elgegren Reátegui, quien desde la sociología, ha realizado el estudio sobre las Semanas Sociales en el Perú (2013), el cual deja pistas muy sugerentes para ayudar a descubrir el fascinante papel de jugó y debe seguir desempeñando la memoria en la permanente tarea de la evangelización. Y, con motivo del centenario del nacimiento del cardenal Juan Landázuri Ricketts, arzobispo de Lima durante estas décadas de profundo cambio eclesial, Carlos Castillo Mattasoglio (2014), ha editado una muy valiosa información de primera mano, que puede ser útil para empezar a elaborar esta anhelada síntesis. 
no escucharemos voces interesadas en desfigurar su labor" (2.4.8) (Conclusiones de la XXXVI Asamblea General del Episcopado Peruano. Lima, 10-25 de Enero de 1969).

A partir de la antropología de la diócesis, -y de la lectura antropológica religiosa de la trayectoria eclesial y de la historia pastoral de la Arquidiócesis de Lima: 1954 1996-, defino la diócesis, como una unidad social que funciona como estructura simbólica de poder de arriba abajo. Que es simbólica, porque concibe como símbolo todo signo, gesto, objeto e incluso acontecimiento, por estar antropológicamente dotado de significado; que, por ser religiosa, tiene como finalidad crear poderosos, convincentes y duraderos estados de ánimo y motivaciones (Geertz 2003:89). Pero que es además, una estructura simbólica de poder piramidal, que ostenta oficialidad, presentándose como natural y sustentándose hasta como sagrada; que exhibe el ejercicio de la autoridad, bajo su tradicional orientación asimétrica descendente, de arriba para abajo.

Sin embargo, esta verticalidad puede ser invertida a causa de determinados factores, tanto exógenos, como propios de la misma iglesia, aunque sobre todo, a causa de la irrupción de un nuevo sujeto y el impulso de una "nueva identidad" (Gutiérrez 2014:102). Es a eso que explícitamente se refiere el Papa, cuando expone su pensamiento acerca de "la inclusión social de los pobres" (186219). Los pobres, insertados en la misma estructura, desde su interior y abismal inferioridad, desde dentro y desde abajo de la misma estructura y su convencional perspectiva vertical, de hecho, permiten emerger otro modo de orientar esa influencia, para administrarlo de manera horizontal y circular hasta conseguir que la estructura deje de ser exclusivamente desigual vertical, de arriba abajo. A fin de transformar actitudes y hechos con que sus actores, resulten haciendo suyos los anhelos y luchas, angustias y esperanzas de los de "abajo".

\section{PARADIGMÁTICA EXPERIENCIA ECLESIAL DE LAS TRILLIZAS DIÓCESIS NUEVAS DE LIMA, PERÚ}

Mientras desde 'arriba', primero el Concilio Vaticano II con sus reformas y luego la Conferencia de Medellín con sus opciones pastorales, los obispos comenzaron a despertar de su letargo a las diócesis del mundo, desde 'abajo', en diócesis fuera del país, como Recife en Brasil, con Hélder Cámara; Riobamba en Ecuador, con Leónidas Proaño; La Rioja en Argentina con Enrique Angelelli ${ }^{12}$; en Cajamarca-Perú, con José Dammert Bellido; y particularmente en Lima, con las oleadas migratorias, Juan Landázuri Ricketts y Augusto Vargas Alzamora, los pastores de la Arquidiócesis se atrevieron a ver y oír desde dentro y desde abajo, para hacer suya no solo la iniciativa sino sobre todo el protagonismo de los migrantes de todas las provincias del Perú, que decidieron asediar de manera "contestataria, masiva y pacífica" (Matos Mar 2011:44.70) la vieja Lima y dar por ocupada la periferia de la metrópoli para desde ella, ejercer su ciudadanía y participar en la marcha del país.

Sobre la base de la diócesis definida como estructura o sistema simbólico de

12 Mientras concluyo este trabajo, el 04 de julio de 2014, en Córdoba Argentina, los miembros de la Diócesis de La Rioja celebran jubilosos la sentencia 38 años esperada, que calificó de 'crimen' el hasta ese momento considerado como 'accidente', la muerte del obispo Enrique Angelelli. Es sumamente significativo comprobar que lo que aquel crimen y esta reivindicación está representando es la legitimación del proyecto de transformar el funcionamiento asimétrico pastoral de la diócesis. 
poder, cuyos signos, gestos o hechos cargados de significado son considerados símbolos, por ser portadores de significado, ¿cómo pensar y analizar la diócesis a partir de lo que vivió la Arquidiócesis de Lima durante la segunda mitad del siglo XX? ¿De qué manera la experiencia con que la Arquidiócesis de Lima gestó tres nuevas diócesis, puede sugerir y proponer un modelo de respuesta actual, real y efectiva a la convocatoria del Papa a la reforma audaz y creativa de las estructuras eclesiales?

Pensar la diócesis, como una unidad social y no solo eclesiástica, que funciona como una estructura simbólica de poder, puede servir para definirla antropológicamente de una manera que ayude a comprender el proceso evangelizador que entraña la historia pastoral de la Arquidiócesis de Lima: 1954-1996. Porque, el que sea concebida como una estructura simbólica de poder, vale por un lado, para tener en cuenta sus orígenes imperiales europeos y para saber que su ingreso violento al mundo de los Andes, determinó instalarse como entidad que funcionó bajo el ejercicio de un poder jerárquico piramidal y vertical, de arriba hacia abajo. Pero que no obstante, por otro lado, puede servir para diferenciar y no reducir el origen, la identidad y la misión de la Iglesia, a los orígenes romanos, medievales e incluso coloniales y republicanos de las diócesis del tercer mundo; y para mostrarla como una unidad social que hizo cambios decisivos, a lo largo de la segunda mitad del siglo XX.

Gracias al impacto del Concilio Vaticano II expresado continentalmente en la Conferencia de Medellín, los hombres y mujeres de la Arquidiócesis de Lima, a partir de la concepción, gestación y aún todavía reciente nacimiento de nuevas diócesis de Lima, emprendieron un proceso opuesto al convencional, que ha llegado a producir un triple fruto. Como producto de su opción preferencial por los pobres, la Arquidiócesis de Lima fue una estructura simbólica de poder inverso, en la que en una relación más emergente y circular que vertical, de mutuo acuerdo, pastores y fieles convinieron en hacer prevalecer la perspectiva de abajo hacia arriba.

Se trata además, de una estructura simbólica de poder, cuyos agentes del clero y del laicado, tras el logro del mutuo acuerdo orientaron el ejercicio de la autoridad, de abajo para arriba, al dejarse interpelar, al hacer suyo y asumir como propio los desafíos sociales y pastorales de las sucesivas oleadas migratorias. Es y funcionó como una estructura simbólica de poder emergente que irrumpió desde abajo, porque para los hombres y mujeres de la Arquidiócesis de Lima, para sus fieles y pastores, el símbolo mayor de su acción pastoral a lo largo de la segunda mitad del siglo XX, fue la larga marcha de la barriada, el mundo de los sectores populares y una constelación de subsiguientes 'símbolos'.

Los fundadores de Ciudad de Dios, seguidos de los fundadores de Pamplona y de Villa El Salvador, se convirtieron en los artífices de una nueva identidad, el campanazo que despertó a los pastores en el funcionamiento de la diócesis como estructura de poder vertical; el sujeto de una nueva relación, que irrumpió protagonizada por las oleadas migratorias, que se hizo presente como expresión de poder de abajo hacia arriba.

Porque cincuenta años antes del decreto pontificio que creó las tres diócesis de Carabayllo, Chosica y Lurín, los fundadores del Cono Sur de Lima, consiguieron despertar la vocación misionera y la misión profética del 
arzobispo, de los sacerdotes y religiosas. Aunque sobre cerros y arenales, pero desde abajo de la estructura social, comenzando de cero, seguidos de los agentes pastorales, los provincianos venidos de todo el Perú tomaron la iniciativa y emprendieron la gesta (Matos Mar 2011:22)13 con que le dieron vida y humanidad al socialmente inexistente, remoto e inaccesible mundo hoy llamado Lima Sur, en que instalaron sus barrios hasta no convertirlos primeramente en capillas, parroquias y distritos.

El nacimiento de las tres últimas diócesis limeñas, particularmente de la de Lurín, es la consumación y punto de llegada de un nuevo funcionamiento pastoral emprendido por la Arquidiócesis de Lima al sur de su jurisdicción, a partir de la invasión de Ciudad de Dios (24-12-54). El prolongado y tenaz nuevo funcionamiento de casi cinco décadas, hizo de la diócesis una estructura simbólica de poder inverso y contrario al acostumbrado ejercicio vertical de la autoridad de arriba abajo. Porque, inspirado en el Evangelio, la población emergente halló lugar en ella, despertando una pertenencia emergente y circular, de abajo para arriba. Y, gracias al espíritu del Concilio y de la Conferencia de Medellín, la Arquidiócesis de Lima plantó los cimientos de otra estructura simbólica de poder: de otro modo de ejercer su presencia eclesial, y de otro modo de administrar su influencia espiritual y social emergente y circular, de abajo hacia arriba.

Es así como se explica que, asumir el impulso conciliar del Vaticano II y hacer suya la memoria de la fundación de Ciudad de Dios, le justificó a la
Arquidiócesis de Lima la creación y aplicación de un nuevo funcionamiento pastoral. Acoger y aplicar Medellín en las diócesis del Perú, condujo a articular la 'gesta' forjadora de Ciudad de Dios con la invasión de Pamplona y el nacimiento de Villa El Salvador; y éstas a su vez, con la visita del Papa Juan Pablo II a los pueblos jóvenes en Villa El Salvador y la irrupción del liderazgo de la mujer popular, dramatizada hasta el extremo con la inmolación de María Elena Moyano.

\section{Estructura simbólica de poder} emergente que permitió que desde Ciudad de Dios, -en la parroquia El Niño Jesús (30-08-58), la primera del Cono Sur-, naciera desde abajo determinado perfil de comunidad cristiana: Comunidad solidaria, crítica y pública que irrumpió y consolidó al hallar unidos en su solidaridad con los invasores de Pamplona, al obispo Bambarén, al párroco La Mazza, con los laicos Manuel Ruiz y Bernardino Panana; al aglutinar en su sentido crítico la voz profética de la comunidad cristiana que deploró la muerte de Edilberto Ramos y el violento trato policial; así como los reclamos del indignado cardenal Landázuri por el encarcelamiento de sus hermanos laicos, sacerdote y obispo; al incentivar y legitimar la conciencia y la participación ciudadana de laicos y laicas que como creyentes, tienen el deber de vivir su fe y su pertenencia católica de manera pública.

\section{CONCLUSIÓN}

¿A partir de qué temprano momento histórico, la Iglesia empezó a vivir en su seno el desgarramiento de sentirse más puro clericalismo y poco o casi

13 Es así, como en su reciente obra el antropólogo José Matos Mar caracteriza y califica "la gesta actual del emergente Perú moderno" para referirse básicamente a su punto de partida, la fundación de la barriada (2011:22). 
nada Pueblo de Dios? ¿Cómo fue que resultó con la mala conciencia de haber abandonado la sobriedad y la fragilidad del Evangelio por el plato de lentejas del lugar eminente y seguro, oficial y holgado en la estructura de poder?

La reforma de las estructuras de la Iglesia, a la que convocaron Juan XXIII, el Concilio y Medellín,-expresado en negación, por Papa Francisco- empezó en el Perú, a partir del reconocimiento y aceptación de la fundación de Ciudad de Dios y de Villa El Salvador; desde el momento que irrumpió por primera vez, el perfil de una comunidad cristiana caracterizada como solidaria porque "está más cerca de la gente"; como crítica: porque "es ámbito de viva comunión y participación"; y como pública: porque "se orienta completamente a la misión" (n. 28).

Porque, de esa manera, pastores y fieles, despertaron, dinamizaron y renovaron la vida de la Arquidiócesis de Lima, sustituyendo aquella su convencional y colonial orientación asimétrica y piramidal, hipotecada a sus privilegios e intereses, por la fragilidad y la simplicidad del Reino; por la tersura misma del Evangelio, cuya fuerza empezó a trabajar como una estructura de poder emergente, horizontal y circular, renunciando a la verticalidad y a los modos antievangélicos de estructurar la marcha de la Iglesia.

¿Cuál fue y puede seguir siendo el aporte de las nuevas diócesis limeñas, y su alto índice de pobladores afincados en asentamientos humanos, el Pueblo de Dios de la periferia limeña, al proyecto del Papa Francisco? Seguir siendo la puesta en evidencia de lo que significa ser vecinos cotidianos de la misma muerte. Del Cristo del Perú real que se ha tomado la Palabra. Que se nos muestra a los creyentes, miembros de las diócesis nuevas alrededor de Lima, del resto de diócesis del Perú y del mundo, como palabra encarnada en la carne de discriminados y empobrecidos hacinados en las faldas de los cerros.

La Diócesis de Lurín -con las de Chosica y Carabayllo-, somos fruto y cosecha abundante a redistribuir $y$ replicar, del primer largo y prolongado empeño encabezado por Juan Landázuri Ricketts y por Augusto Vargas Alzamora. Haciendo suyas la iniciativa y el protagonismo, las luchas y esperanzas de los provincianos venidos de todo el Perú, estos pastores al lado de su rebaño, renunciaron a la estructura simbólica de poder, administrada habitualmente de manera vertical, caracterizada por muy largo tiempo, por "un excesivo clericalismo" (102). Porque prefirieron con Isaías $(42,3)$ "la mecha humeante" y "las cañas quebradas" del Evangelio con que puede identificarse las poblaciones de la periferia limeña.

Estas tres diócesis, tuvieron su difícil concepción y audaz gestación a partir del episcopado del cardenal Juan Landázuri Ricketts, seguido del cardenal Augusto Vargas Alzamora, que con gran apertura, iniciativa y creatividad lograron ser fieles a las reformas estructurales del Concilio y Medellín. Difícil, porque fue un proceso postergado, desde la Conquista y la Colonia. Audaz, porque fue el resultado de un largo proceso contra corriente, de los que suele tener en contra la misma ley de la gravedad. Con razón, del primero, con motivo del centenario de su nacimiento, Gustavo Gutiérrez ha hecho hace poco la siguiente remembranza que da cuenta de este doble proceso, y del perfil de diócesis que ambos cardenales fieles a su pueblo consiguieron construir, y que hoy el Papa Francisco está echando de menos: 
"Aunque, convencido de lo que le correspondía como obispo, Juan Landázuri Ricketts- nunca fue ajeno a la circunstancia nacional en la medida en que ella afectaba la vida y el destino de aquellos a quienes se debía como pastor. Esa actitud le valió el respeto de las autoridades políticas del país que sabían que estaban ante alguien que, consciente de la inspiración evangélica de su misión como cabeza de la Iglesia peruana, no callaba, por eso mismo, ante la injusticia social y la situación de los pobres. Y si bien no faltaron algunas opiniones distintas, era una voz que recibía un gran consenso en la nación." (Gutiérrez 2014:89)

De razón, José Ramón Gurruchaga, salesiano de origen vasco, diez años obispo de Huaraz durante las décadas de violencia armada, y actualmente obispo emérito supo orientar su episcopado como primer obispo de la Diócesis de Lurín, con dos lemas que caracterizan sugerentemente los motivos y objetivos de la necesidad de este proceso de refundación universal de la diócesis: pensando acaso en el pasado reciente como en el remoto colonial arriba mencionado, el Padre Obispo solía decir "Tenemos más futuro que pasado"; y reclamando la elaboración y aplicación de un plan pastoral que venga de abajo, que contenga y responda a la realidad integral de los hombres y mujeres de su Iglesia local, dejó resonando en el corazón de sacerdotes, religiosas y laicos "iYo quiero una diócesis viva!"

\section{REFERENCIAS:}

ARGUEDAS, J. M. (1966) Dioses y Hombres de Huarochirí. Traducción y prólogo. Apéndice por Museo Nacional de Historia e Instituto de Estudios Peruanos.
CASTILlO M., C. (2014) Caminando en el amor. El pastor de una Iglesia viva. Homenaje al cardenal Juan Landázuri Ricketts en el centenario de su nacimiento. Fondo Editorial de la PUCP.

ELGEGREN, F. (2013) "Estudio de la Obra de la Iglesia Peruana en las Semanas Sociales Nacionales 1958-2008". Revista Phainomenon del Departamento de Filosofía y Teología. Facultad de Psicología y Humanidades. Volumen 12, $\mathrm{n}^{\circ} 1$. Lima: UNIFE.

EPISCOPADO PERUANO, (1969) Conclusiones de la XXXVI Asamblea General del Episcopado Peruano. (Lima, 10-25 de Enero de 1969)

GEERTZ, C. (2003) La interpretación de las culturas. Madrid: Gedisa.

GUTIÉRREZ, G. (2014) El Cardenal Landázuri, por una Iglesia servidora (85), en Castillo 2014, Caminando en el amor. El pastor de una Iglesia viva. Homenaje al cardenal Juan Landázuri Ricketts en el centenario de su nacimiento. Fondo Editorial de la PUCP

GUTIÉRREZ, G. (2014) Entre las calandrias. Un ensayo sobre José María Arguedas. Lima: Biblioteca Nacional del Perú.

MATOS MAR, J. (2012) Perú: Estado desbordado y sociedad nacional emergente. Centro de Investigación Universidad Ricardo Palma. Lima: Editorial Universitaria.

OSORIO TORRES, J. A. (2013). Tradición y utopía pastoral. Antropología de la Diócesis desde el nacimiento de la Diócesis de Lurín: 1954-1996. Tesis de Doctorado en Antropología en la PUCP. 
ROMERO, C. y TOVAR, C. (1987ª) "Cambios en la Iglesia Peruana". En CEHILA Vol. VIII Perú, Bolivia, Ecuador Edic. Sígueme, pp. 417-446.

SÁNCHEZ, J. y CURÁTOLA, M. (Eds) (2013). Los rostros de la tierra encantada: religión, evangelización y sincretismo en el nuevo mundo Homenaje a Manuel Marzal, s.j. Lima: Fondo Editorial de la PUCP.

TAYLOR, G. (1999) Ritos y tradiciones de Huarochirí. Instituto Francés de Estudios Andinos. Banco central de Reserva del Perú, Universidad Particular Ricardo Palma. 